\title{
Translation as a Cross Cultural Study: An Analysis of Scent of a Woman
}

\author{
Amineh Adelnia \\ Feizoleslam University \\ Isfahan, Iran
}

Received: 10-10-2014

doi:10.7575/aiac.ijclts.v.3n.1p.24
Accepted: 28-11- 2014

Published: 01-01- 2015

\begin{abstract}
Translation is a profession that deals with replacing a message in one language by a similar message in another language. However, this is not always possible in translation of Culture-Bound Terms (CBTs) since each culture has its own way of expressing concepts and entities. When translating CBTs of a text, the translator should be cautious of the strategies he/she chooses to better be able to transfer the effect that the original writer assumes to transfer. This paper aims to investigate the procedures used by the translator to translate CBTs from English into Farsi. These CBTs are chosen from one single scene of the movie Scent of a Woman. In order to do so, the researcher watched the film and extracted the CBTs from the subtitles and analyzed the data. The paper also provides the readers with some examples to see how the translator coped with the difficulty of his rendering.
\end{abstract}

\section{Keywords: Culture, Culture-Bound Terms (CBTs), Translation Strategies, Subtitles}

\section{Introduction}

Many scholars proposed different definitions for the term of translation. Catford (1965), for example, defined translation as comprising a "substitution of target language meanings for source language meanings." He tried to notice that texts constitutenot primarily of languages but in fact of cultures. Language can be regarded as an expression of culture which can influence the way the speakers of that culture perceive the world. Thus, translation here is not just a transfer of information between languages but a transfer from one culture to another (Hervey et al., 1995:20).

Cross cultural communication is receiving much attention nowadays and translation of cultural terms is a very challenging task for the translator. There are some items heavily rooted in one culture and speakers of other cultures lack such terms. It is the task of the translator to find the closest natural equivalents according to the purpose of his translation and also according to the audience he is translating the text for.

\subsection{Translation as a Cross Cultural Activity}

Translation can be regarded as an activity that mainly deals with transference between two cultures rather than between two languages. Nowadays all the people across the world are forming and exchanging new ideas and translation can play an important role in facilitating the process.

Newmark states that "translation is a craft consisting in the attempt to replace a written message and/or statement in one language by the same message and/or statement in another language" (New mark, 1981:7). However, with culturally bound words, this is not always possible. The meaning which lies behind such cultural expressions is strongly linked to the specific cultural context where the text originates.

Sometimes cultural terms have their exact cultural equivalents in the target language: therefore, they can be easily rendered. However, in most cases the translator is faced with cultural complexities and difficulties. The original readers have some background cultural knowledge that the target language readers lack. In order to solve such complexities the translator should choose the most appropriate strategies for his translation.

\subsection{Cultural Translation in Media}

Culture-bound problems are not only pertaining to the translation of texts. In the case of dubbing and film translation we are faced with such problems too. Dealing with register, different accents and dialects, and informal use of English is a serious problem imposed to film translation. Some believes that these problems are not related to culture but Goodenough states the opposite: "by definition, we should note that culture is not a material phenomenon; it does not consist of things, people, behavior or emotions. It is rather an organization of these things. It is the form of things that people have in mind, their model of perceiving and dealing with their circumstances" (Goodenough, 1964:36). So we can infer that the way people talk, and the situation they are in can be part of their cultures.

The aim of this paper is to define some cases of culture-bound elements in the English subtitles of the film Scent of a Woman directed by Martin Brest in the USA in 1992. The present study is not a criticism of the translation of the film. The researcher will only try to make a comparison between the English source text the Persian target text and define some culture-bound elements to show the techniques the translator made use of in order to cope with these cultural 
differences and difficulties which are identified during the process of translation. The researcher will pay attention both to the positive and negative aspects of his rendering.

The scene chosen from Scent of a Woman is the one in which a student named Charles is going to meet Colonel Slade for the first time. The Colonel is blind and thus seeking for an attendant. Charles is the right attendant for him because he is in great need of money to be able to give his family a visit in Oregon during his Christmas holiday. They are going to have an interview to get familiar with each other.

The subtitle of the original English film is compared with that of Persian to see how the translator transferred CBTs. Under each translation, there is transcription to make it readable for those who are not familiar with Persian language.

\section{Methodology}

If we look at the film's text from the linguistic point of view, we see that because of the harsh and impolite character of the Colonel, he uses an informal language and almost a colloquial tone. He makes use of verbs like "gonna" and "wanna", gerunds like "shootin" and "doin" and the pronoun "ya".

ST: - Come a little closer. I wanna get a better look at ya.

TT: Bia jelotar, mikham behtar bebinamet.

As you notice, the translator of the film could not translate this tone into Persian and because the target language lacks such tone he preferred to use the standard language and translate it formally.

Because Mr. Slade is a colonel, his words and his language is similar to a military service man. He tries to send his atendant away by shouting:

\section{ST: - Dismissed}

TT: Morakhasi

The translator here successfully transferred this martial language via his translation. The word he used as the exact equivalent shows the superiority of the Colonel Slade over the attendant as the way a colonel is superior over their soldiers in the armed forces.

Finding good equivalents by the translator is shown also in another part of the interview when Charlie is calling Mr. Slade before they go deep into the conversation.

\section{ST: -Sir?}

- Don’t call me sir!

- Sorry, I meant mister, sir.

\section{TT: Ghorban?}

Man ro ghorban seda nakon!

Bebakhshid manzoram jenab bood, ghorban.

In this part of the conversation, young Charles is trying to find a right title for the colonel. So he tries to be more formal by choosing the word sir. But when he sees the Colonel's refusal he corrects himself by the word mister. The equivalents used here are very appropriate as in Persian (ghorban) is more formal than (jenab). So the translator skillfully has translated these culture-specific terms which better shows the relationship between the characters.

More culture-bound elements can be found in this particular scene, which are all linked to the American culture. The example from the ST, I am going to analyze, is the expression card telephone in the statement by the Colonel.

ST: -your father peddles card-telephones at a three-hundred percent mark-up.

TT: pedaret telephone mashin ro ba se barabare gheimat mifroshe.

Card telephones were used among American people in 1990. They are big and not handy devices which could work by the insertion of a card in a slot. So the close equivalent for it can be (telephone karti).

Convenience store is another cultural word that belongs to the American society. Charles uses the term when he wants to talk about his parents job. This word can be regarded as a cultural item because $\mathrm{i}$ is related to the way people work to have a living. It indicates their way of life in general and shows the lifestyle of the people at that time.

ST: - my stepfather and my mom run a convenience store.

TT: napedarie man va madaram ye maghazeye lavazem khanegi darand.

These convenience stores are very popular in the USA and stay open 24 hours a day. They sell food, newspapers and gasoline and they are generally located along roads and even in gas stations. It seems that the translator has not been successful in rendering this expression. In Persian culture (maghazeye lavazem khanegi) can not be found in gas stations and they do not sell food or newspapers. In American culture these convenience stores are somehow like the drugstores found in cities and are totally different with the Persian equivalent the translator decided to choose for this culturebound term. 
Related to the American's lifestyle and habits, there is the expression of Clinique, which shows the high standard of the Americans' lives. After talking about his skin to the Colonel, Charles explains:

ST: - well, I...I've had a few zits.

Um, but my roommate, he lent me his Clinique because he's from...

TT: khob man chandtayi josh dashtam.

Vali ham otaghim keremesh ro behem gharz dad be khatere inke oon ahle...

The word Clinique is translated generally as (kerem). Clinique is the brand name for the product which people from the higher ranks of society use. Unfortunately by choosing the general equivalent for this term, the translator could not communicate this special meaning and the Target audience could not understand the point that Clinique is for higher ranks.

Prep school is the term which is associated with social structure of the American society and of its institution.

ST: - you givin' me that old prep school palaver?

TT: por harfihaye doreye dabestanet ro baraye man avordi?

The term prep school refers to a school which is paid for by parents but in the translation it is translated as the primary school which is not a correct equivalent at all. A better equivalent for it can be (madreseye gheire entefayi). Here we can infer that the translator lacks the required knowledge about the American society and took primary school for prep school mistakenly and did not achieve the communicative effect.

A very interesting point to mention in the translation of this scene is when the translator translated wood chips in Frank's question.

ST: - what does your daddy do in Gresham, Oregon?

\section{Hmm? Count wood chips?}

TT: pedaret dar Gresham Oregon chi kar mikone?

Teke chobha ro mishmore?

Here, the Colonel tries to humiliate Charles, because he is superior, by mentioning such expression. Wood chips refer to unimportant things, residue of wood of little use, and also refer to doing things of no significance. The translator here translated the term literally and ignored that his translation might not carry the meaning intended by the original text.

\subsection{Translation Strategies Used to Translate CBTs of the Film}

Facing with culture-bound terms, a translator should make use of some techniques and strategies to fill the gap which exists between the two cultures. Here the researcher noticed that there are three major procedures used in rendering the original text into Farsi: substitution, paraphrase, deletion.

2.1.1 Substitution is the time when the translator substitutes a terms in the source text with another different term in the target text. Like the use of (maghazeye lavazem khanegi) as an equivalent for the Convenience store.

2.1.2 Paraphrase is a method of making the original meaning more clear by using other words to express it. When a difficult cultural word is noticed by the translator, he may use this technique and over translate it by clarifying more in the target language. Like the term (por harfihaye doreye dabestanet) instead of prep school palaver.

2.1.3 Deletion refers to an expression in the source language that is simply omitted in the text in the target language or that the culture-bound element in it is not preserved. In some cases because the translator can not find the proper equivalent, he prefers to eliminate some aspects of meaning from that particular term which leads the audience not to communicate the intended meaning by the original text. Like (mikham behtar bebinamet) for the term I wanna get a better look at ya.

Although these techniques are different from each other, all of them carry the same purpose toward the words and terms which belong to the source language culture. The general purpose is to make the foreign become familiar. The terms which may not be understood by the audience of the target language are transformed into something else. These techniques may bring new and different meanings not present in the original. They may even loose the culture-bound elements totally. But they do it just because they try to achieve clarity and naturalness to help the audience to better comprehend the film.

\section{Conclusion}

It can be concluded that theoretically a text which is embedded in its culture is both possible and impossible to be translated into other languages. If practicality is considered first, however, every translation is possible. The degree of its closeness to its source culture and the extent to which the meaning of its source text is to be retained will be very much determined by the purpose of the translation and how deep the source text is embedded in the culture. The more source-text-oriented a translation is, the more difficult it is to do. Similarly, the deeper a text is embedded in its culture, the more difficult it is to work on. 
References

Catford, J.C.(1965). A Linguistic Theory of Translation: an Essay in Applied Linguistic. London: Oxford University Press.

Goodenough, Ward H. (1964). "Cultural Anthropology and Linguistics" in D.Hymes (ed). Language in Culture and Society. A reader in Linguistics and Anthropology. New York: Harper \& Row.

Hervey, S. \& Higgins, I., (1992). Thinking Translation. A Course in Translation Method: French-English. London and New York: Routledge.

Martin, B. (1992). Scent of a Woman. Universal Pictures.

Newmark, P. (1981). Approaches to Translation. Oxford Pergamon Press. 